\title{
Variability of Vaginal pH Determination by Patients and Clinicians
}

\author{
Daron G. Ferris, MD, Sean L. Francis, MD, Eileen D. Dickman, PhD, MBA, CCRC, \\ Kimberly Miler-Miles, MD, Jennifer L. Waller, PhD, and Nora McClendon
}

Purpose: Measurement of intravaginal $\mathrm{pH}$ provides a reasonable assessment of vaginal health but is fraught with the potential for several sampling errors. The purposes of the study were to determine the variability of self-sampled vaginal $\mathrm{pH}$ among women using an inexpensive swab-based $\mathrm{pH}$ test compared with a clinician-obtained specimen, and variability of vaginal $\mathrm{pH}$ within 3 regions of the normal vagina.

Methods: In this cross-sectional study, women obtained a vaginal specimen using a cotton-tip applicator, transferred it to $\mathrm{pH}$ paper, and interpreted the results. A clinician also blindly interpreted these tests. Thereafter, a clinician obtained 3 swab specimens from the proximal, middle, and distal vagina for $\mathrm{pH}$ testing. Results were compared using Wilcoxon signed rank test, interclass correlation coefficients, Bland-Altman plots, and mixed-model analysis of variance.

Results: Interclass correlation coefficients were moderately high comparing subjects with clinician for the swab-based pH test (0.74). Subjects' swab pH values (4.5) were significantly lower than clinicians' $\mathrm{pH}$ values $(4.7, P=.0001)$. Intravaginal $\mathrm{pH}$ did not vary between the 3 anatomic locations.

Conclusions: Self-sampled intravaginal pH interpretations vary slightly compared with clinicianobtained specimens. Because swab pH sampling does not detect an intravaginal pH gradient in normal women, self-sampling technique may vary considerably without affecting outcomes. Our findings support self-sampling for vaginal $\mathrm{pH}$ before using over-the-counter products for presumed vaginitis. (J Am Board Fam Med 2006;19:368-73.)

The normal vaginal ecosystem in mature women is maintained by Lactobacilli species that secrete lactic acid and hydrogen peroxide. A resulting $\mathrm{pH}$ $<4.7$ is thought to limit the overgrowth of opportunistic microbes. Consequently, vaginal secretions are clear, non-irritating and void of offensive odor. More importantly, potentially serious gynecological and obstetrical complications arising from an abnormal vaginal ecosystem associated with bacterial vaginosis are prevented. ${ }^{1}$

Assessment of intravaginal $\mathrm{pH}$ is a helpful, but frequently neglected, diagnostic procedure used to evaluate vaginal health. ${ }^{2}$ Because microscopic eval-

Submitted 6 December 2005; revised 31 January 2006; accepted 7 February 2006.

From the Departments of Family Medicine (DGF, EDD), Obstetrics and Gynecology (DGF, SLF, KM-M, NM), and Biostatistics (JLW), The Medical College of Georgia, Augusta, GA.

Funding: Supported in part by an unrestricted research grant from Johnson \& Johnson Pharmaceutical Research and Development.

Conflict of interest: none declared.

Corresponding author: Daron G. Ferris, MD, Department of Family Medicine, The Medical College of Georgia, 1423 Harper Street, HH-105, Augusta, GA 30912 (E-mail: dferris@mcg.edu). uation of vaginal secretions is prone to misdiagnosis, a simple $\mathrm{pH}$ determination assumes even greater importance with respect to Amsel's criteria used to clinically diagnose bacterial vaginosis. Clinicians usually obtain vaginal secretions or discharge from the lateral vaginal walls with a small cotton-tip applicator. The moist specimen is then transferred to a strip of $\mathrm{pH}$ paper and compared with a standardized colorimetric reference chart to estimate actual $\mathrm{pH}$. With respect to diagnosing vaginitis, an elevated $\mathrm{pH}$ suggests Trichomonas vaginitis or bacterial vaginosis. Vulvovaginal candidiasis is generally detected in a normal vaginal $\mathrm{pH}$ range $(<4.7)$.

Patient self-diagnosis and self-treatment of vulvovaginal candidiasis is fraught with error. ${ }^{3-6}$ Twothirds of women who purchase over-the-counter antimycotics for treatment of self-diagnosed vulvovaginal candidiasis do not have vulvovaginal candidiasis. ${ }^{3}$ An easy, rapid and inexpensive self-diagnostic test for vaginitis may help to minimize the tendency to self-treat vaginitis inappropriately. Self-collected vaginal samples may be as accurate as clinician-obtained specimens for diagnosing various sexually transmitted infections including Neis- 
seria gonorrhea, Chlamydia trachomatis, Trichomonas vaginalis, and human papillomavirus. ${ }^{7-13}$ Moreover, self-sampling the vagina seems to be very acceptable to women of multiple ethnic groups. ${ }^{8,9,13-17}$ Women have also demonstrated a willingness to obtain a self-sample of vaginal secretions for Gram stain detection of bacterial vaginosis. ${ }^{18} \mathrm{~A}$ self $\mathrm{pH}$ test of vaginal secretions would permit a relatively simpler appraisal of vaginal ecosystem status. ${ }^{19,20}$ However, $\mathrm{pH}$ within the vagina is not uniform and depending on location, becomes less acidic toward the introitus. ${ }^{21}$ In addition, false elevations of $\mathrm{pH}$ may be encountered when semen, mucus, or blood is inadvertently sampled. Because self-sampling of vaginal secretions may vary in technique (depth, duration, and position) among women, $\mathrm{pH}$ results may also vary accordingly. The purpose of this study was to determine the variability of self-sampled vaginal $\mathrm{pH}$ among normal women using an inexpensive swab-based $\mathrm{pH}$ assessment method compared with clinician-obtained specimens. We also assessed variability of vaginal $\mathrm{pH}$ within 3 regions of the vagina as measured by a clinician. The ultimate goal of our research program is to enhance knowledge and proper use of vaginal $\mathrm{pH}$ self-sampling, particularly for women considering over the counter treatment of presumed vulvovaginal candidiasis.

\section{Subjects and Methods}

A convenience sample of women 18 years of age and older, and without vaginal symptoms, was passively recruited (using pamphlets) to participate from clinics at the Medical College of Georgia. Women who were pregnant, menstruating, or had a known vaginal or cervical infection were excluded. The study was approved by the Institutional Review Board.

All subjects were informed of the cross-sectional study requirements and signed an informed consent document. Only subjects with a negative urine human chorionic gonadotropin test result were allowed to continue. Demographic and gynecologic information was obtained and subjects were asked to read a one-page instruction sheet that described the techniques for self-measurement of vaginal $\mathrm{pH}$. Subjects held a cotton-tip applicator between their thumb and index finger and inserted the swab into the vagina. They then were instructed to rotate the swab clockwise and counter-clockwise while attempting to touch the vaginal sidewalls. Subjects removed the swab, placed it on a strip of $\mathrm{pH}$ paper (pHydrion paper; Micro Essential Laboratory, Brooklyn, NY), and independently compared the color of the $\mathrm{pH}$ paper with the standard $\mathrm{pH}$ color reference chart $(\mathrm{pH} 3.0-5.5)$ to determine their self-obtained $\mathrm{pH}$ test results. At the same time, a clinician with normal color vision also independently determined the $\mathrm{pH}$ results of subjects' selfobtained specimens. Immediately afterward, the clinician inserted a vaginal speculum and obtained 3 specimens from the proximal, middle, and distal vagina using different cotton-tip applicators. Secretions from the swabs were transferred to other strips of the same type of $\mathrm{pH}$ paper (pHydrion) to determine clinician-obtained $\mathrm{pH}$ results from the 3 regions of the vagina.

Descriptive statistics were calculated for all demographic and clinical variables. To examine whether the interpretation of $\mathrm{pH}$ within the vagina was similar between clinician and subjects, several analyses were performed. First, Wilcoxon's signed rank tests (due to the non-normality of the data) were used to examine whether median $\mathrm{pH}$ results were different between subjects and clinician. Second, interclass correlation coefficients (ICC) were determined for reliability of swab-based $\mathrm{pH}$ tests for subjects and for clinician. Third, a Bland-Altman plot was constructed for subjects versus clinician for the swab-based $\mathrm{pH}$ tests. The intent of this study was to determine concordance and not accuracy of $\mathrm{pH}$ determinations because a criterion standard test (in vivo $\mathrm{pH}$ meter) was not included. Consequently, the final analysis determined agreement between subject's and clinician normal $(<4.7)$ and abnormal $(\geq 4.7) \mathrm{pH}$ results using $\kappa$ statistic.

To examine differences in $\mathrm{pH}$ level between the proximal, middle, and distal vaginal area, a mixed model analysis was used. First, the unadjusted means were examined in a one-factor model. Next, potential covariates of age, race, parity, hormone replacement therapy, and birth control were added to the one-factor model. Finally, a backward model building process was used to remove any covariate that was not statistically significant at an $\alpha$ level of 0.05 . The final model consisted of the vaginal area factor and any covariates that were statistically significant at the $0.05 \alpha$ level. A Tukey multiple comparison procedure was used to examine pair-wise differences post hoc in the adjusted least square means of the $\mathrm{pH}$ in the different vaginal areas. 
Table 1. Demographic Statistics $(n=113)$

\begin{tabular}{lcr}
\hline Variable & & \\
\hline Race (n, \%) & & \\
$\quad$ Black & 53 & $(46.9)$ \\
White & 55 & $(48.7)$ \\
Asian & 0 & $(0.0)$ \\
Hispanic & 3 & $(2.7)$ \\
Other & 2 & $(1.8)$ \\
Age (mean, SD) & 35.1 & $(10.1)$ \\
Height (mean, SD)† & 64.7 & $(3.2)$ \\
Weight (mean, SD) & 171.8 & $(45.3)$ \\
Gravida (mean, SD) & 2.0 & $(1.7)$ \\
Parity (mean, SD) & 1.7 & $(1.5)$ \\
Abortion (mean, SD) & 0.3 & $(0.7)$ \\
Vaginal births (mean, SD) & 1.5 & $(1.5)$ \\
Cesarean sections (mean, SD) & 0.3 & $(0.7)$ \\
Regular periods (n, \%) & 78 & $(69.0)$ \\
Pelvic surgery (n, \%) & 28 & $(24.8)$ \\
Vaginal medications (n, \%) & 1 & $(0.9)$ \\
Hormone replacement therapy (n, \%) & 11 & $(9.7)$ \\
Birth control method (n, \%) & & \\
$\quad$ None & 36 & $(31.9)$ \\
Surgical & 27 & $(23.9)$ \\
Other $\neq$ & 50 & $(44.3)$ \\
\hline
\end{tabular}

* Height in inches.

$\dagger$ Weight in pounds.

‡ Includes birth control pills, barrier methods, progesterone injection, transdermal, intrauterine device, and abstinence.

All statistical significance was assessed using an $\alpha$ level of 0.05 , and all statistical analyses were performed using SAS 8.2.

\section{Results}

A total of 113 subjects participated in the study. Descriptive statistics for all demographic and clinical variables are given in Table 1 . In general, the population could be summarized as representing mainly blacks and whites, middle-aged, overweight, and multiparous women.

Subjects' and clinician mean intravaginal $\mathrm{pH}$ interpretations and SD for the subject-collected swab method were $4.5(0.5)$ and $4.7(0.5)$, respectively.

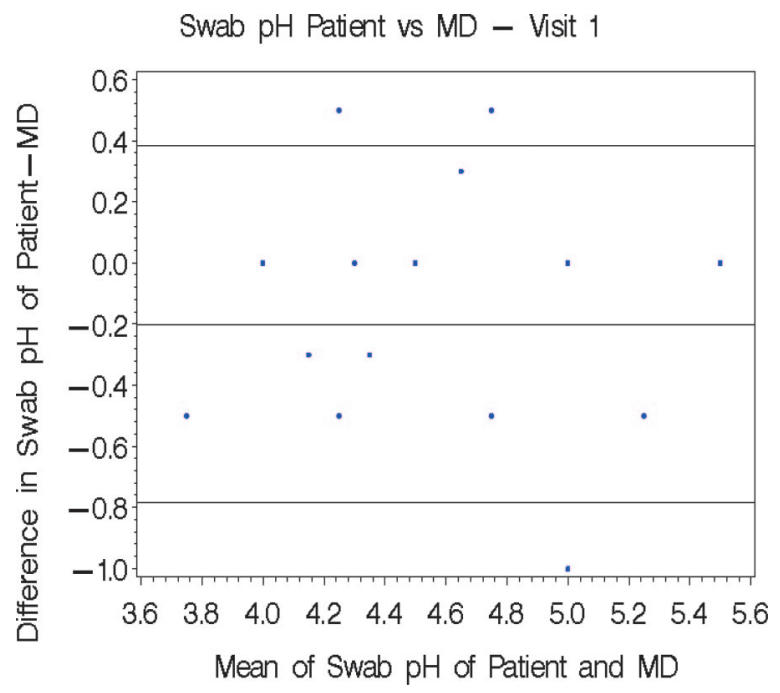

Figure 1. Bland-Altman plot for differences in swab pH as determined by subjects and the clinician. $\mathrm{pH}$ values had minimal variability between observers.

ICC and Wilcoxon's signed rank tests were used to compare results between subjects and clinician for the swab-based $\mathrm{pH}$ tests (Table 2). Comparing subjects with clinician for the swab-based $\mathrm{pH}$ test, the ICC values were moderately high (0.74) indicating good reliability. The Wilcoxon signed rank test result indicated that the median $\mathrm{pH}$ values were different. Subjects' $\mathrm{pH}$ values (4.5) were significantly lower than clinician $\mathrm{pH}$ values $(4.6, P=$ .0001). There was moderate agreement between subjects' and clinician interpreted normal and abnormal $\mathrm{pH}$ results $(\kappa=0.67,95 \%$ CI $0.52-0.81)$.

A Bland-Altman plot was used to portray variability of $\mathrm{pH}$ results using the swab (Figure 1). Most points lie inside the $1.96 \mathrm{SD}$ limits indicating that the agreement between subjects and clinician for swab $\mathrm{pH}$ testing was very good.

Mean intravaginal $\mathrm{pH}$ results using a cliniciandirected swab sampling method of the proximal, middle and distal vagina were calculated. These values varied little; $4.6(0.7), 4.5$ (0.5) and $4.5(0.4)$, respectively. A mixed model analysis was then used to determine $\mathrm{pH}$ result differences by intravaginal

Table 2. Comparison of Samplers and Intravaginal pH Sampling Methods

\begin{tabular}{lcccccc}
\hline Swab-based $\mathrm{pH}$ test & Mean $\mathrm{pH}$ & $\mathrm{SD}$ & Median $\mathrm{pH}$ & ICC $^{*}$ & $\mathrm{~S}$ & $P$ Value \\
\hline Subject & 4.5 & 0.5 & 4.5 & 0.74 & -538.0 & .0001 \\
Clinician & 4.7 & 0.5 & 4.6 & & & \\
\hline
\end{tabular}

* ICC, interclass correlation coefficients; S, Wilcoxon's signed rank test. 


\begin{tabular}{|c|c|c|c|c|}
\hline \multirow[b]{2}{*}{ Model } & \multicolumn{2}{|c|}{ Adjusted Least Square } & \multirow[b]{2}{*}{ F Value } & \multirow[b]{2}{*}{$P$ Value } \\
\hline & Mean & SE & & \\
\hline \multicolumn{5}{|l|}{ Unadjusted model } \\
\hline Vaginal area & & & 0.84 & .43 \\
\hline Proximal & 4.60 & 0.07 & & \\
\hline Middle & 4.52 & 0.05 & & \\
\hline Distal & 4.54 & 0.04 & & \\
\hline \multicolumn{5}{|l|}{ Full model } \\
\hline Age & & & 1.22 & .27 \\
\hline Parity & & & 7.04 & .01 \\
\hline Race & & & 3.47 & .02 \\
\hline Hormone replacement therapy & & & 1.06 & .31 \\
\hline Birth control & & & 3.29 & .07 \\
\hline Vaginal area & & & 0.61 & .54 \\
\hline Proximal & 4.59 & 0.12 & & \\
\hline Middle & 4.53 & 0.11 & & \\
\hline Distal & 4.53 & 0.11 & & \\
\hline \multicolumn{5}{|l|}{ Final model } \\
\hline Parity & & & 10.40 & .002 \\
\hline Race & & & 4.17 & .008 \\
\hline Vaginal area & & & 0.61 & .54 \\
\hline Proximal & 4.61 & 0.11 & & \\
\hline Middle & 4.55 & 0.09 & & \\
\hline Distal & 4.55 & 0.09 & & \\
\hline
\end{tabular}

sampling site (Table 3). There were no differences in $\mathrm{pH}$ between the 3 vaginal areas in any models. This indicates that in these women, little variation in the $\mathrm{pH}$ was seen regardless of intravaginal sampling area.

\section{Discussion}

Experienced clinicians realize the importance of measuring intravaginal $\mathrm{pH}$ to determine the status of the vaginal ecosystem. Although ignored by many clinicians, Amsel's criteria for the clinical assessment of bacterial vaginosis considers $\mathrm{pH}$, in addition to amine odor, adherent vaginal discharge, and presence of clue cells. ${ }^{22}$ The latter assessment requires a microscope, transport media, glass slides, and cover slips. Moreover, it involves considerable training, careful scrutiny, and several minutes of appraisal. In contrast, the $\mathrm{pH}$ test is less complicated, much cheaper and results are available immediately. Because of its simplicity, ability to improve health care, and potential appeal to women, self-assessment of the vagina using $\mathrm{pH}$ paper was critically evaluated.
We demonstrated minor differences in $\mathrm{pH}$ interpretations between women and a clinician when a swab was used for sampling. Although women reported significantly lower $\mathrm{pH}$ values on average when compared with the clinician, these differences were not clinically meaningful. Specifically, the mean $\mathrm{pH}$ result by subjects was considered normal, and the clinician's mean $\mathrm{pH}$ result may be interpreted as borderline normal. Although moderate agreement was observed between subject's and clinician $\mathrm{pH}$ interpretations, it is important to note that the self-testing results of women may vary slightly from their clinicians' results. This potential for minor discordance may occasionally create confusion and management dilemmas for both patients and health care providers. A careful clinical evaluation and further laboratory testing should be undertaken when symptoms or a self $\mathrm{pH}$ test result raise diagnostic questions.

Much to our surprise, there was no difference in intravaginal $\mathrm{pH}$ by region when assessed by a clinician using a swab and $\mathrm{pH}$ paper. Others have described a $\mathrm{pH}$ gradient within the normal vagina using more sophisticated testing devices, ${ }^{21}$ but the 
swab and $\mathrm{pH}$ paper method may not have been sensitive enough to detect small changes of $\mathrm{pH}$ throughout the normal vagina. In an evaluation of a different $\mathrm{pH}$ paper (range 4.5-7.5) compared with a $\mathrm{pH}$ meter for assessing intravaginal $\mathrm{pH}$, the $\mathrm{pH}$ paper had a correlation coefficient of 0.87 , but a mean $\mathrm{pH}$ difference of $0.95 .^{23}$ Because no in vivo $\mathrm{pH}$ meter was used in our study as a criterion standard, we were unable to determine whether women or the clinician rendered more accurate assessments. However, the intent of our study was to determine concordance and not accuracy.

Any variation of $\mathrm{pH}$ interpretations in normal asymptomatic women seems to be clinically irrelevant as measured by women and a clinician. Although clinicians can make an effort to avoid sampling mucus, blood, and semen to minimize falsely elevated $\mathrm{pH}$ results, this task was thought to be more challenging for self-testing. Our results proved otherwise. The brief self-sampling instructions perhaps contributed to retrieving optimal specimens. Women can also be educated to avoid sampling after sexual intercourse and while menstruating to minimize spurious results. Our concern about how women sample for $\mathrm{pH}$ within the vagina may be tempered by these results that indicate little significant variation of intravaginal $\mathrm{pH}$ using simple sampling devices.

Recently, an over-the-counter vaginal self $\mathrm{pH}$ test was approved for use by the FDA. ${ }^{19,24}$ However, this device is considerably more expensive and does not use a swab for sampling purposes. Instead, a small strip of $\mathrm{pH}$ paper mounted at the end of the sampler is used to obtain the specimen although the $\mathrm{pH}$ paper is considered for in vitro use only. Further, the $\mathrm{pH}$ scale may not adequately reflect a reasonable range of intravaginal $\mathrm{pH}$ because it only records values $\geq 4.5$. Our $\mathrm{pH}$ paper values ranged from 3.0 to 5.5 , more closely approximating usual normal or abnormal vaginal $\mathrm{pH}$ results.

One limitation of our study was that it included only asymptomatic women. It would be interesting to repeat our study in a population of symptomatic women to determine variation of $\mathrm{pH}$ within the abnormal vagina. One goal of this study was to determine whether a clinician could detect the normal intravaginal $\mathrm{pH}$ gradient using a swab to $\mathrm{pH}$ paper technique. This gradient would not exist in patients with an elevated $\mathrm{pH}$ as seen with bacterial vaginosis and Trichomonas vaginitis. A study of women with abnormal vaginal discharge should evaluate clinician/patient $\mathrm{pH}$ test variability and subsequent decision making as to the need of additional assessment by a health care provider. If symptomatic women perform similarly to clinicians, the medical community would be more confident in endorsing self-sampling of vaginal $\mathrm{pH}$.

Our findings have important clinical relevance for women's health care. First, women are able to self-sample the vagina and measure intravaginal $\mathrm{pH}$. Self-sampling and testing empowers women to become more involved with their medical care. The less intrusive technique can be done in private to minimize embarrassment. Furthermore, sampling can occur at a time suitable for women and not necessarily when convenient for a health care provider. More importantly, women's vaginal $\mathrm{pH}$ results were very similar to those measured by a medical provider. This concordance extends the examination room and laboratory to accommodate women in countless locations. Knowledge of intravaginal $\mathrm{pH}$ can guide women before selecting to inappropriately use over-the-counter products for vaginitis. Very simply, in symptomatic women, a high vaginal $\mathrm{pH}$ result would require further evaluation (if not premenarchal or postmenopausal) by a health care provider. A normal $\mathrm{pH}$ in symptomatic women would suggest vulvovaginal candidiasis prompting more selective use of an over-thecounter product. A better informed self-diagnosis would ultimately reduce individual financial expenditures, delayed treatment, and possible secondary complications. $^{3,6}$ It would also lower health care cost for the medical industry. ${ }^{25}$ Based on our results, self-sampling of vaginal $\mathrm{pH}$ seems very suitable for implementation and should help improve health care for women. ${ }^{26}$

\section{References}

1. Soper DE. Gynecologic complications of bacterial vaginosis: fact or fiction. Am Inf Dis Rep 1999;1: 393-7.

2. Wiesenfeld HC, Macio I. The infrequent use of office-based diagnostic tests for vaginitis. Am J Obstet Gynecol 1999;181:39-41.

3. Ferris DG, Nyirjesy P, Sobel JD, Soper D, Pavletic A, Litaker MS. Over-the-counter antifungal drug misuse associated with patient-diagnosed vulvovaginal candidiasis. Obstet Gynecol 2002;99:419-25.

4. Ferris DG, Dekle C, Litaker MS. Women's use of over-the-counter antifungal medications for gynecologic symptoms. J Fam Pract 1996;42:595-600. 
5. Lipsky M, Waters T. The "Prescription-to-OTC Switch" movement. Arch Fam Med 1999;8:297-300.

6. Sihvo S, Ahonen R, Mikander H, Hemminki, E. Self-medication with vaginal antifungal drugs: physicians' experiences and women's utilization patterns. Fam Pract 2000;17:145-9.

7. Petignat P, Hankins C, Walmsley S, Money D, Provencher D. Canadian Women's HIV Study Group. Self-sampling is associated with increased detection of human papillomavirus DNA in the genital tract of $\mathrm{HIV}$-seropositive women. Clin Infect Dis 2005;41:527-34.

8. Lack N, West B, Jeffries D, et al. Comparison of non-invasive sampling methods for detection of HPV in rural African women. Sex Transm Infect 2005;81:239-41.

9. Dannecker C, Siebert U, Thaler CJ, Kiermeir D, Hepp H, Hillemanns P. Primary cervical cancer screening by self-sampling of human papillomavirus DNA in internal medicine outpatient clinics. Ann Oncol 2004;15:863-9.

10. Harper DM, Longacre MR, Noll WW, Belloni DR, Cole BF. Factors affecting the detection rate of human papillomavirus. Ann Fam Med 2003;1:221-7.

11. Shafer MA, Moncada J, Boyer CB, Betsinger K, Flinn SD, Schachter J. Comparing first-void urine specimens, self-collected vaginal swabs, and endocervical specimens to detect Chlamydia trachomatis and Neisseria gonorrboeae by nucleic acid amplification test. J Clin Microbiol 2003;41:4395-9.

12. Knox J, Tabrizi SN, Miller P, et al. Evaluation of self-collected samples in contrast to practitioner-collected samples for detection of Chlamydia trachomatis, Neisseria gonorrhoeae, and Trichomonas vaginalis by polymerase chain reaction among women living in remote areas. Sex Transm Dis 2002;29:647-54.

13. Harper DM, Noll WW, Belloni DR, Cole BF. Randomized clinical trial of PCR-determined human papillomavirus detection methods: self-sampling versus clinician-directed-biologic concordance and women's preferences. Am J Obstet Gynecol 2002; 186:365-73.

14. Tebb KP, Paukku MH, Pai-Dhungat MR, Gyamfi AA, Shafer MA. Home STI testing: the adolescent female's opinion. J Adolesc Health 2004;35:462-7.

15. Forrest S, McCaffery K, Waller J, et al. Attitudes to self-sampling for HPV among Indian, Pakistani, Af-
rican-Caribbean and white British women in Manchester, UK. J Med Screen 2004;11:85-8.

16. Richardson E, Sellors JW, Mackinnon S, et al. Prevalence of Chlamydia trachomatis infections and specimen collection preference among women, using self-collected vaginal swabs in community settings. Sex Transm Dis 2003;30:880-5.

17. Dzuba IG, Diaz EY, Allen B, et al. The acceptability of self-collected samples for HPV testing vs. the pap test as alternatives in cervical cancer screening. J Womens Health Gend Based Med 2002;11:265-75.

18. Boskey ER, Atherly-Trim SA, O'Campo PJ, Strobino DM, Misra DP. Acceptability of a selfsampling technique to collect vaginal smears for gram stain diagnosis of bacterial vaginosis. Womens Health Issues 2004;14:14-8.

19. Roy S, Cailloutte JC, Faden JS, Roy T, Ramos DE. Improving appropriate use of antifungal medications: the role of an over-the-counter vaginal $\mathrm{pH}$ self-test device. Infect Dis Obstet Gynecol 2003;11: 209-16.

20. Saling E, Schreiber M, Al-Taie T. A simple, efficient and inexpensive program for preventing prematurity. J Perinat Med 2001;29:199-211.

21. Kistner RW. Physiology of the vagina in human reproductive medicine. In: Hafez ESE, Evans TN, editors. The human vagina. Vol 2. New York: North-Holland; 1978. p. 109.

22. Amsel R, Totten PA, Spiegel CA, et al. Nonspecific vaginitis diagnostic criteria and microbial and epidemiologic association. Am J Med 1983;74:14-22.

23. Khandalavala J, Van Geem TA. Evaluating vaginal $\mathrm{pH}$, accuracy of two commercial $\mathrm{pH}$ papers in comparison to a hand-held digital $\mathrm{pH}$ meter. J Reprod Med 1999;44:76-80.

24. Roy S, Caillouette JC, Faden JS, Roy T. The role of an over-the-counter vaginal $\mathrm{pH}$ self-test device package insert: can subjects learn what the device is for and how to use it?. Am J Obstet Gynecol 2005; 192:1963-9.

25. Lipsky M, Waters T, Sharp L. Impact of vaginal antifungal products on the utilization of health care services: evidence from physician visits. J Am Bd Fam Pract 2000;13:178-82.

26. Lowe N, Ryan-Wenger N. A clinical test of women's self-diagnosis of genitourinary infections. Clin Nurs Res 2000;9:144-60. 